\title{
Gas-liquid two-phase flow behavior in terrain-inclined pipelines for gathering transport system of wet natural gas
}

\author{
Yang, Yan; Li, Jingbo; Wang, Shuli; Wen, Chuang
}

Published in:

International Journal of Pressure Vessels and Piping

Link to article, DOI:

10.1016/j.ijpvp.2018.03.005

Publication date:

2018

Document Version

Peer reviewed version

Link back to DTU Orbit

Citation (APA):

Yang, Y., Li, J., Wang, S., \& Wen, C. (2018). Gas-liquid two-phase flow behavior in terrain-inclined pipelines for gathering transport system of wet natural gas. International Journal of Pressure Vessels and Piping, 162, 52-58. https://doi.org/10.1016/j.ijpvp.2018.03.005

\section{General rights}

Copyright and moral rights for the publications made accessible in the public portal are retained by the authors and/or other copyright owners and it is a condition of accessing publications that users recognise and abide by the legal requirements associated with these rights.

- Users may download and print one copy of any publication from the public portal for the purpose of private study or research.

- You may not further distribute the material or use it for any profit-making activity or commercial gain

- You may freely distribute the URL identifying the publication in the public portal 
1 Gas-liquid two-phase flow behavior in terrain-inclined pipelines for

\section{gathering transport system of wet natural gas}

$$
\text { Yan Yang }{ }^{1} \text {, Jingbo } \mathrm{Li}^{1} \text {, Shuli Wang }{ }^{1} \text {, Chuang Wen }{ }^{2, *}
$$

${ }^{1}$ School of Petroleum Engineering, Changzhou University, Zhonglou District, Changzhou, 213016, China

$$
{ }^{2} \text { Department of Mechanical Engineering, Technical University of Denmark, Nils }
$$
Koppels Allé, 2800 Kgs. Lyngby, Denmark

*Corresponding author. Tel.: +45 45254168; fax: +45 45251961. E-mail address: cwen@mek.dtu.dk (C. Wen).

Abstract: The Volume of Fluid method and Re-Normalisation Group (RNG) $k-\varepsilon$ turbulence model were employed to predict the gas-liquid two-phase flow in a terraininclined pipeline with deposited liquids. The simulation was carried out in a $22.5 \mathrm{~m}$ terrain-inclined pipeline with a $150 \mathrm{~mm}$ internal diameter. The flow parameters were numerically analyzed in detail including the phase distribution in pipes, the velocity and pressure around the elbow, the liquid flow rate and liquid holdup in different crosssection and the volume of liquid outflow. The numerical results presented that a wave crest formed on the liquid level under the suction force which caused by the negative pressure around the elbow, and then it touched to the top of the pipe. When the liquid blocked the pipe, the pressure drop between the upstream and downstream of the elbow increased with the increase of the gas velocity. At larger gas velocity, more liquid was carried out to the pipeline. The liquid periodically flowed and returned along the uphill section when the liquid was no longer flowing out of the pipeline.

Keywords: terrain-inclined pipeline; natural gas; liquid loading; gas-liquid two-phase flow; Volume of Fluid 


\section{Introduction}

During the development of condensate natural gas fields, such as the Puguang Gas Field in China's Sichuan Basin, there are many uphill and downhill pipes due to the large rolling terrain. The liquid often accumulates in the low section of the pipeline during the wet natural gas transportation. The deposited liquid may block the pipeline under the action of the gaseous phase and cause the sharp fluctuation of pressure [1]. It affects the normal operation of the pipeline, even damages the conveying equipment. In addition, the pipeline is more easily subjected to the corrosion issues [2, 3], because the deposited liquid is difficult to be removed. Therefore, it is significant to study the flow behavior of the deposited liquid in the wet natural gas pipelines.

The gas-liquid two-phase flows in the horizontal and inclined pipes have been studied for decades. Taitel et al. [4] proposed a model to calculate the flow behavior under the transient flow conditions in a hilly-terrain pipeline system. The model was applied to the low liquid and gas flow rates, where the frictional pressure losses could be neglected. Grolman and Fortuin [5] modified the apparent rough surface model to predict the pressure gradient and liquid holdup in slightly inclined pipes. Salhi, et al. [6] improved the one-dimensional two-fluid model to study the stability of stratified gas-liquid two-phase flows in an inclined pipe. Goldstein et al. [7] proposed the exact solutions for the laminar stratified flows in the inclined pipes. The solution could be used for investigating the influence of the pipe inclination and flow geometry on the liquid holdup and pressure gradient. Gawas et al. [8] proposed a new wave celerity correlation for the gas-liquid two-phase stratified flow using the low viscosity fluids and compared with a mechanistic model proposed by Watson. The Poisson probability theory was employed to predict the slug frequency in the gas-liquid horizontal pipelines [9]. The results indicated that the theoretical model resulted in a great improvement 
with the average error of $15 \%$ for $1.2 \mathrm{~m} / \mathrm{s}$ and $0.4 \mathrm{~m} / \mathrm{s}$ superficial liquid velocities.

51 Ferrari et al. [10] developed a novel two-fluid model to capture the slug flow in pipes using a one-dimensional transient hyperbolic five-equation. This theoretical model successfully captured the slug onset, growing, and development from a stratified flow in horizontal pipes.

Barnea and Shoham [11] carried out an experimental study in an air-water system with $2.55 \mathrm{~cm}$ and $1.95 \mathrm{~cm}$ pipes and compared with the theoretical prediction of Taitel and Dukler. The results showed that the experiment data agreed with the theoretical prediction. Tzotzi and Andritsos [12] gave a modified form of Andritsos-Hanratty model to study stratified gas-liquid two-phase flow and estimate pressure drop and

60 interfacial friction factor in a horizontal pipe. Jia et al. [13] used two absolute pressure sensors to measure differential pressure and obtained the void fraction from differential pressure model in a horizontal gas-liquid two-phase pipe. Arunkumar et al. [14] used the dielectric sensors to identify the gas-liquid two-phase flow regime. The bubbly, slug and stratified flow regimes could be identified in their experiments. Abdulkadir et al. [15] investigated the unsteady hydrodynamic behaviour of slug flow in a horizontal pipe using the an air-silicone oil mixture as the working fluid. Their results showed that the drift velocity component of the bubbles in horizontal pipes far exceeds the value found for vertical riser pipes. Dinaryanto et al. [16] experimentally studied the initiation and flow development mechanisms of the gas-liquid two-phase slug flow in a horizontal pipe., The initiation frequency of slug flow and the evolution of passing slug frequency

71 along the pipeline were also observed by using two high video cameras in their experiments. Bouyahiaoui et al. [17] employed intermediary of the conductance probe technique to study the slug flow behavior in the vertical downward air-water two-phase 
74 pipelines. The experimental results showed that the mean averaged void fraction 75 increased with the gas superficial velocity.

The numerical simulation approach was employed to predict the flow regime and

flow characteristics of gas-liquid two-phase flows. Mouza et al. [18] used computational fluid dynamics (CFD) modeling to simulate the wave stratified twophase flow in a horizontal pipe. The distribution of the shear stresses and the velocity profiles of both phases were calculated by using CFD modeling. Loilier [19] applied the two-fluid model to simulate the gas-liquid two-phase flow in vertical and terraininclined pipelines consisting of the uphill, downhill and horizontal sections. The vertical bubble flow, stratified and terrain-inclined slug flows were simulated and the avoid fraction, slug frequency, slug length and other parameters were obtained in this work. Ekambara et al. [20] performed a numerical study of the bubbly two-phase flow in a horizontal pipeline. The numerical results agreed well with the experimental data. Vallee et al. [21] investigated the stratified and slug flow by using the CFD modeling, particle image velocimetry and high-speed video observation experiments. The main flow characteristics obtained by the CFD modeling were successfully validated against the experiments. Verdin et al. [22] used the CFD modeling for simulating the transport behavior of water droplets in 38 in. diameter pipes and compared the oil flow behavior and droplets with that of water. Santim et al. [23] compared different methodologies in transient isothermal gas-liquid two-phase slug flows in a horizontal pipeline. The comparison studies indicated that the Drift-Flux Model presented the better agreement with the pressure wave velocity by the experiments. Wang et al. [24] developed a fluidstructure interaction dynamic model for the conveying severe slugging flow in a pipeline-riser system. Their results showed that the dynamic response of the riser is 
closely related to the characteristics of severe slugging, which can be used to eliminate severe slugging phenomenon to improve the stability of the riser system.

The gas-liquid two-phase flows in horizontal and vertical pipelines attract a great many of experimental and numerical studies, while the flow mechanism of the gathering liquids in the elbow of hilly-terrain pipes is still not understood very well. The purpose of this work is to study the gas-liquid two-phase flow in the terraininclined pipelines to obtain local and global flow characteristics using the CFD modeling, which can provide the detailed information for removing the deposited liquid effectively and correspondingly protecting natural gas pipeline and equipment. The Volume of Fluid (VOF) method and Re-Normalisation Group (RNG) $k$ - $\varepsilon$ turbulence model are used to predict the deposited liquid motion under the action of the gaseous phase in the terrain-inclined pipeline system including an uphill section and a downhill section. The flow parameters are analyzed in detail, including the velocity and pressure distribution, phase fraction and cross-section liquid holdup.

\section{Terrain-inclined pipelines}

The terrain-inclined pipeline is employed for our current studies, which contains a downhill section and an uphill part. The inclination angles of downhill and uphill segments are both assigned to be $5^{\circ}$. It is assumed that a certain amount of liquids is gathering at the bottom of the inclined pipeline system, as shown in Fig. 1. The threedimensional geometry of terrain-inclined pipeline is established for the computational domain, including the pipe diameter of $D=150 \mathrm{~mm}$ and the length of every section is $75 \mathrm{D}$, which ensures a fully developed flow for this terrain-inclined pipeline system. 


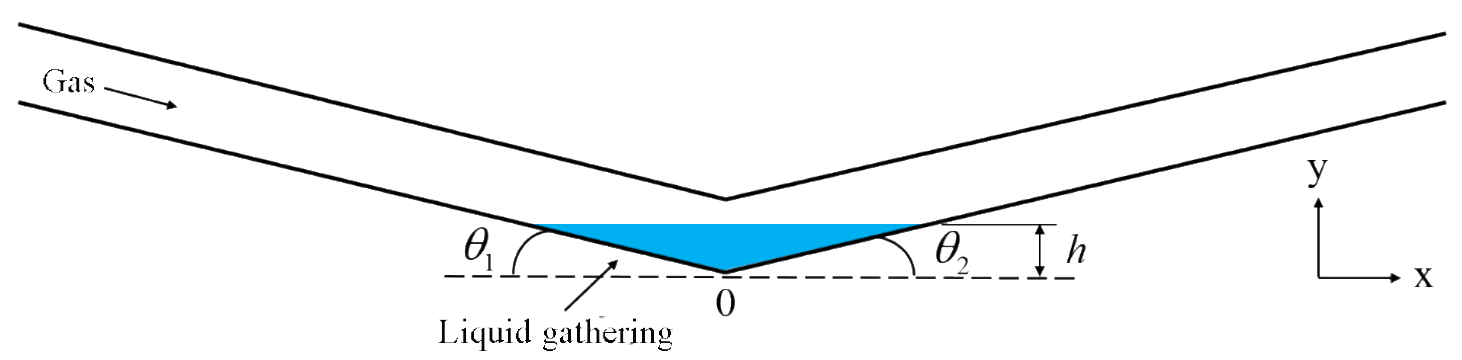

Fig. 1 Terrain-inclined pipelines

The flow data for the gas-liquid two-phase is presented in Table 1, obtained from Puguang gas field in Sichuan Basin of China. The working fluids are methane and water, respectively. In this case, the solubility of methane in water can be neglected, we, therefore, assume that the water and methane are the immiscible fluids in the numerical studies.

Table 1 Flow data for gas-liquid two-phase numerical simulation

\begin{tabular}{cccccccc}
\hline Case & $\begin{array}{c}U_{G} \\
\left(\mathrm{~m} \mathrm{~s}^{-1}\right)\end{array}$ & $\begin{array}{c}\rho_{G} \\
\left(\mathrm{~kg} \mathrm{~m}^{-3}\right)\end{array}$ & $\begin{array}{c}\mu_{G} \\
\left(\mathrm{~m}^{2} \mathrm{~s}^{-1}\right)\end{array}$ & $\begin{array}{c}h / D \\
(-)\end{array}$ & $\begin{array}{c}V_{L} \\
\left(\mathrm{~m}^{3}\right)\end{array}$ & $\begin{array}{c}\rho_{L} \\
\left(\mathrm{~kg} \mathrm{~m}^{-3}\right)\end{array}$ & $\begin{array}{c}\mu_{L} \\
\left(\mathrm{~m}^{2} \mathrm{~s}^{-1}\right)\end{array}$ \\
\hline 1 & 5.5 & 0.6679 & $1.087 \times 10^{-5}$ & 0.75 & 0.01637 & 998.2 & 0.001003 \\
2 & 6.5 & 0.6679 & $1.087 \times 10^{-5}$ & 0.75 & 0.01637 & 998.2 & 0.001003 \\
3 & 7.5 & 0.6679 & $1.087 \times 10^{-5}$ & 0.75 & 0.01637 & 998.2 & 0.001003
\end{tabular}

\section{Computational methods}

\subsection{Governing equations}

The gas-liquid two-phase flow in the terrain-inclined pipeline represents a distinct phase interface. The interface catching is a key issue for our simulation of this kind of flow behavior. The VOF model [25] uses the surface-tracking technology based on the fixed Eulerian mesh, which can be employed to model two or more immiscible fluids. Therefore, we utilize the VOF model here to track the gas-liquid phase interface in the terrain-inclined pipelines. 
The continuity equation is as follows [26]:

$$
\frac{\partial \rho}{\partial t}+\frac{\partial}{\partial x_{i}}\left(\rho u_{i}\right)=0
$$
the velocity field is shared among all the phases.

$$
\frac{\partial}{\partial t}(\rho \vec{u})+\nabla \cdot(\rho \vec{u} \vec{u})=-\nabla p+\nabla \cdot\left[\mu\left(\nabla \vec{u}+\nabla \vec{u}^{T}\right)\right]+\rho \vec{g}+\vec{F}
$$

142

151 follows [28]:

$$
\frac{1}{\rho_{q}}\left[\frac{\partial}{\partial t}\left(\alpha_{q} \rho_{q}\right)+\nabla \cdot\left(\alpha_{q} \rho_{q} u_{q}\right)=\sum_{p=1}^{n}\left(\dot{m}_{p q}-\dot{m}_{q p}\right)\right]
$$

where $\rho$ is the density, $u$ is the velocity, $p$ is the static pressure, $\mu$ is the dynamic viscosity, $\overrightarrow{\rho g}$ is the gravitational body force and $\vec{F}$ is external body force.

For the gas-liquid two-phase flow, the $\rho$ and $\mu$ in each computational cell are given by the following equations:

domain. The interface between two phases is tracked by solving the continuity equation for the volume fraction of one (or more) phases. The volume fraction equation is as where $\dot{m}_{p q}$ is the mass transfer from phase $q$ to phase $p$ and $\dot{m}_{q p}$ is the mass transfer from phase $p$ to phase $q, \alpha_{q}$ is the volume fraction of phase $q$. The primary phase volume fraction is solved based on the following constraint:

\subsection{Continuum surface force model}

$$
\sum_{q=1}^{n} \alpha_{q}=1
$$


160 It is implemented as a source term in the momentum equation. The pressure drop across

161 the surface depends on the surface coefficient $\sigma$ and the surface curvature are measured

162 by two radii in orthogonal directions $R_{1}, R_{2}$ :

$$
p_{1}-p_{2}=\sigma\left(\frac{1}{R_{1}}+\frac{1}{R_{2}}\right)
$$

The surface force $F_{v o l}$ is expressed as follows:

$$
F_{v o l}=\sigma_{i j} \frac{\rho \kappa_{i} \nabla \alpha_{i}}{\frac{1}{2}\left(\rho_{1}+\rho_{2}\right)}
$$

166

\subsection{Turbulence model}

Among the $k-\varepsilon, k-\omega$ and Reynolds stress models [30-32], the RNG $k-\varepsilon$ turbulence model [33] involves an additional term to its dissipation rate equation that can improve the accuracy for rapidly strained flow. The swirling effect on the turbulence is also included in the RNG $k-\varepsilon$ model. Both of these two modifications show that the RNG $k$ $\varepsilon$ model is more suitable for the prediction of the large curvature and strain rate flow in the terrain-inclined pipelines. Therefore, the RNG $k-\varepsilon$ turbulence model is employed here, because the flow turns at the elbow of the pipe, which connects the uphill section and downhill section in terrain-inclined pipelines. The turbulence kinetic energy, $k$, and its rate of dissipation, $\varepsilon$, are as follows:

$$
\begin{gathered}
\frac{\partial(\rho k)}{\partial t}+\frac{\partial\left(\rho k u_{i}\right)}{\partial x_{i}}=\frac{\partial}{\partial x_{j}}\left[\alpha_{k} \mu_{e f f} \frac{\partial k}{\partial x_{j}}\right]+G_{k}+G_{b}-\rho \varepsilon-Y_{M} \\
\frac{\partial(\rho \varepsilon)}{\partial t}+\frac{\partial\left(\rho \varepsilon u_{i}\right)}{\partial x_{i}}=\frac{\partial}{\partial x_{j}}\left[\alpha_{\varepsilon} \mu_{e f f} \frac{\partial \varepsilon}{\partial x_{j}}\right]+\frac{C_{1 \varepsilon} \varepsilon}{k}\left(G_{k}+C_{3 \varepsilon} G_{b}\right)-C_{2 \varepsilon} \rho \frac{\varepsilon^{2}}{k}-R_{\varepsilon}
\end{gathered}
$$

where $G_{k}$ represents the generation of turbulence kinetic energy due to the mean velocity gradients, $G_{b}$ is the generation of turbulence kinetic energy due to buoyancy, $Y_{M}$ represents the contribution of the fluctuating dilatation in compressible turbulence to the overall dissipation rate. $\alpha_{k}$ and $\alpha_{\varepsilon}$ are the inverse effective Prandtl numbers for $k$ and $\varepsilon$, respectively. 


\subsection{Numerical schemes}

The pressure-based VOF method and the RNG $k-\varepsilon$ turbulence model are employed for the computation of the gas-liquid two-phase flow in the terrain-inclined pipeline. The VOF explicit scheme is performed for accurately tracking the surface between the gaseous and liquid phases [34]. In addition, the effect of the body force is considered, including the gravity and the surface force. The pressure-velocity coupling is the PISO algorithm. The continuity equation, momentum equation and turbulence equations are discretized with the QUICK method, while the Geometric Reconstruction scheme (Geo-Reconstruct) is chosen for the volume fraction equation.

The structured mesh is adopted as the strategy of the grid system for the whole computational domain. The velocity-inlet and outflow boundary conditions are set for the inlet and outlet of the calculation model. The residual of the calculation is set to $10^{-}$ ${ }^{5}$, and the maximal iterations per time step is 20 . The time step size is $10^{-4} \mathrm{~s}$ for proving the calculation convergence in every time step.

\section{Results and discussion}

\subsection{CFD validation}

The numerical method was validated with the experiments carried out by Heywood and Richardson [35] before we applied it to the gas-liquid two-phase flows in the terrain-inclined pipeline. The liquid holdup of a slug flow was measured by $\gamma$-ray absorption method in a horizontal pipeline with $42 \mathrm{~mm}$ inner diameter and $457 \mathrm{~m}$ length. The average results of the experimental data were estimated by the probability density functions. The working fluids were air and water, respectively. For the CFD model validation, we utilized six group experimental data in the different gas superficial velocities, while the liquid superficial velocity was fixed at $0.978 \mathrm{~m} / \mathrm{s}$. The comparison of the slug flow in a horizontal pipe was described in Fig. 2. The similar flow behavior 
of liquid holdup in the slug flow was presented between the simulations and experiments. The maximum relative error was approximate $5.9 \%$ occurring at the gas superficial velocities of $4.145 \mathrm{~m} / \mathrm{s}$. Therefore, our numerical simulation agreed well

211 with the experimental data.

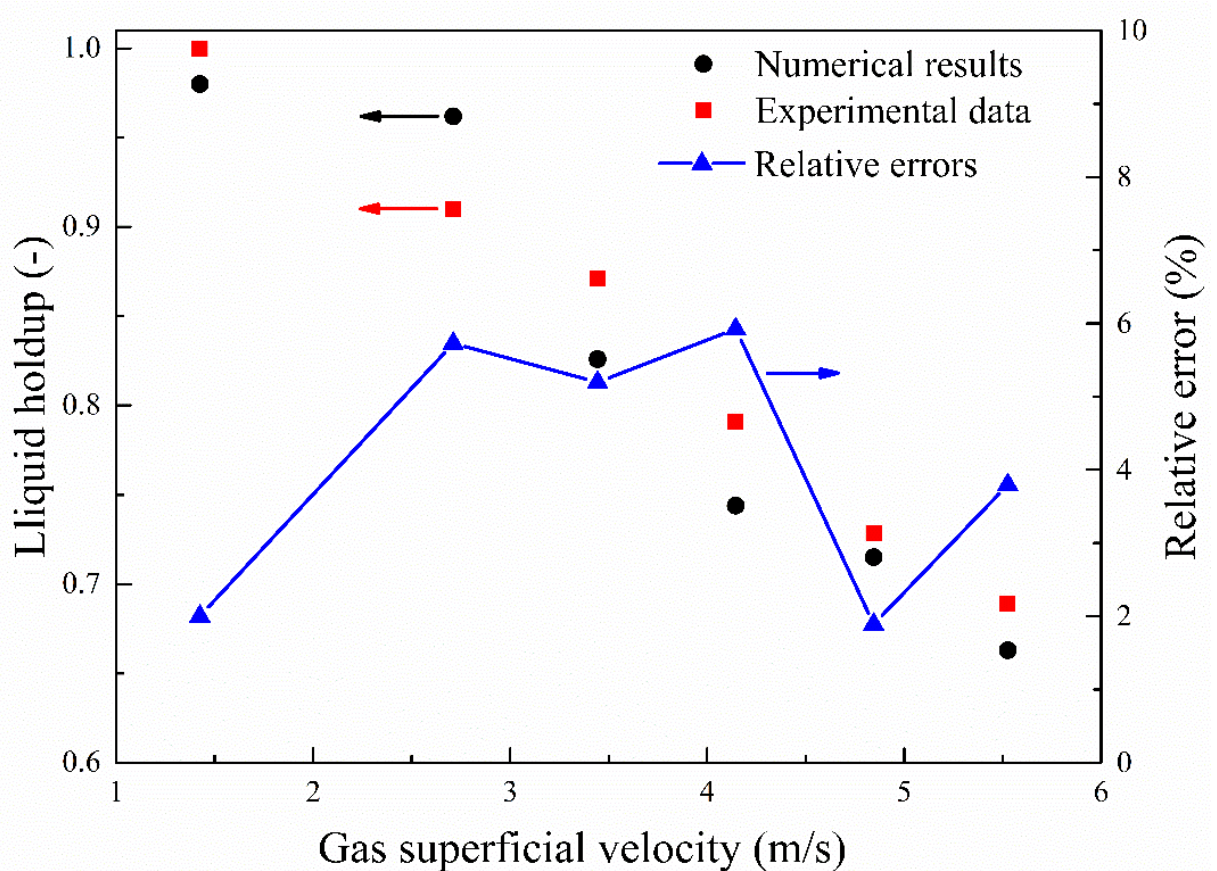

Fig. 2. Liquid holdup in a slug flow

\subsection{Process of liquid touched to the top of pipe}

Fig. 3 shows the phase distribution near the elbow of the terrain-inclined pipe at different times with inlet gas velocity of $U_{G}=5.5 \mathrm{~m} / \mathrm{s}$. The blue contour presents the gaseous phase, while the red one reveals the liquid phase. The gas-liquid phase interface

218 was disturbed when the gaseous phase flowed through the interface of the liquid phase.

219 A wave crest gradually formed in the gas-liquid interface at $t=0.005 \mathrm{~s}-0.085 \mathrm{~s}$. Then

220 the wave crest continued to become larger and moved along the gas flow direction at 221 the same time ( $t=0.095 \mathrm{~s}-0.105 \mathrm{~s}$ in Fig. 3). At $t=0.115 \mathrm{~s}$, the wave crest touched to the top of the pipe and then filled the whole cross-section of the pipe at this point. 


\section{Flow Direction}

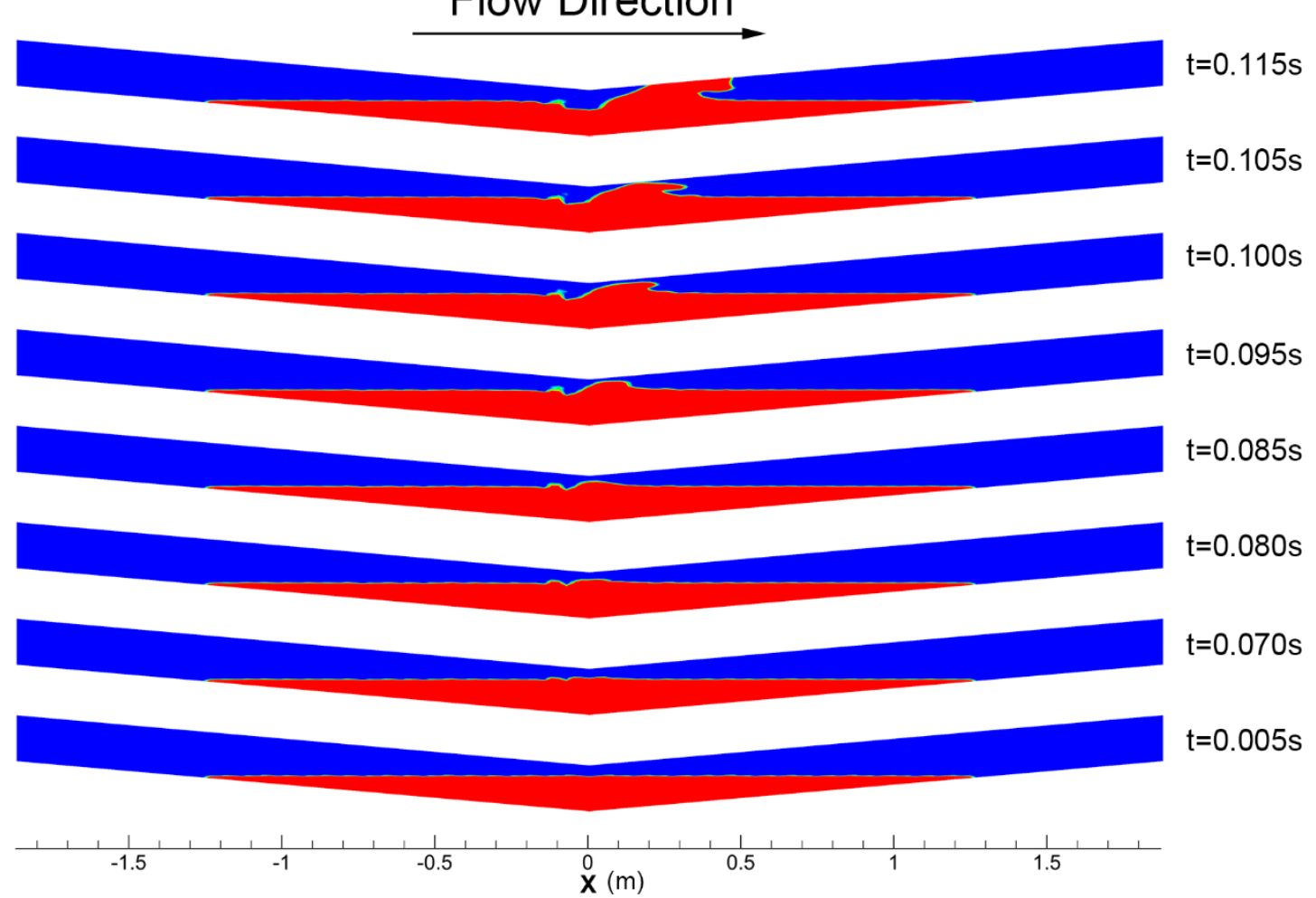

Fig. 3. Gas and liquid phase distribution in the terrain-inclined pipes

The distribution of velocity magnitude and static pressure near the elbow are

shown in Fig. 4. It represents that the gas velocity obviously increased when the gaseous phase flows through the region above the liquid, and the maximum velocity can reach

$22836 \mathrm{~m} / \mathrm{s}$ at $t=0.005 \mathrm{~s}$. The gas flow area decreased due to the liquids assembled at the

229 bottom of the pipe, which caused the increase of the gas velocity when the gaseous

230 phase went through the region. At $t=0.085 \mathrm{~s}$, the gaseous phase flowed through the

231 top of the wave crest and then it was accelerated. At $t=0.115 \mathrm{~s}$, the distribution of

232 velocity in the pipe was different from the first two time steps due to the gaseous phase

233 was separated to two discontinuous regions by the liquid phase.

234 The pressure difference appeared around the elbow of the terrain-inclined pipe at $235 t=0.005 \mathrm{~s}$ due to the increase of the gas velocity. The gas-liquid phase interface was 236 disturbed and then the wave crest formed due to the large suction force overcoming the 237 effect of the gravity. At $t=0.085 \mathrm{~s}$, the pressure difference region moved to the 
downstream of the elbow and the suction force was directed to this region. The wave crest correspondingly continued to become larger and moved to the downstream of the

240 elbow. At $t=0.115 \mathrm{~s}$, some amount of the liquids filled the whole cross-section of the

241 pipe and the gaseous phase was divided into two parts. The upstream pressure is higher 242 than the downstream one. The liquids moved by the action of the pressure difference 243 between the upstream and downstream.

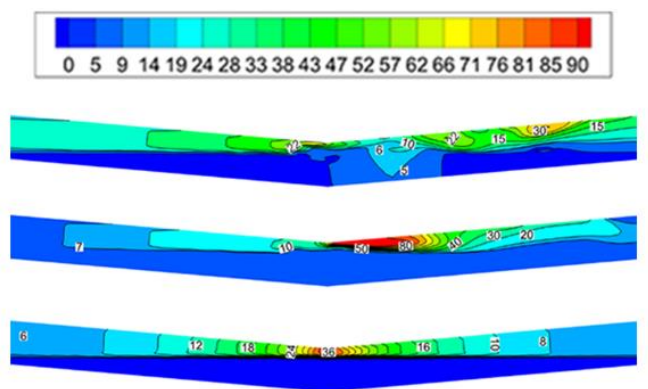

(a) Velocity magnitude

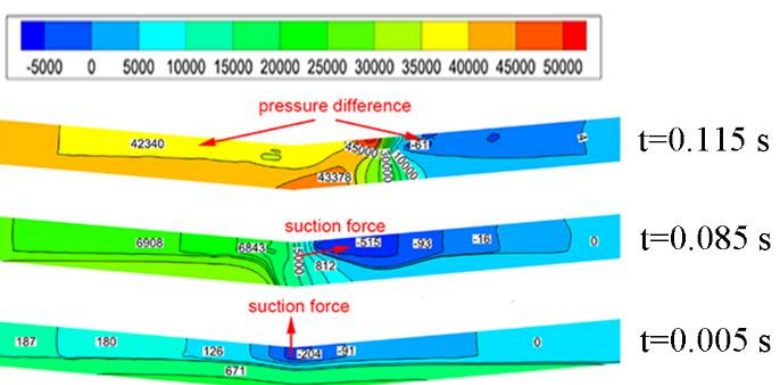

(b) Static Pressure

Fig. 4 Velocity and static pressure in the terrain-inclined pipes

\subsection{Liquid motion along the uphill section}

The gaseous and liquid phase distributions along the uphill section are shown in Fig. 5. The blue and red contours present the gaseous and liquid phase, respecively. We can see that the liquid phase blocked the pipe cross-section like a water plug after the liquid touched to the top of the pipe. It continued to move under the action of the pressure difference between the upstream and downstream, and some liquids moved along the top of the pipe and fell under the action of the gravity $(t=0.12 \mathrm{~s}-0.40 \mathrm{~s})$. At $t=0.80 \mathrm{~s}-5.0 \mathrm{~s}$, the liquid motioned to the pipe outlet and some liquids flowed out the pipe exit under the action of the inertia and the shearing force of the gaseous phase. At $t=6.0 \mathrm{~s}-9.8 \mathrm{~s}$, the remanent liquids refluxed to the elbow and the gravity played a dominant role in this fluid flow process. 

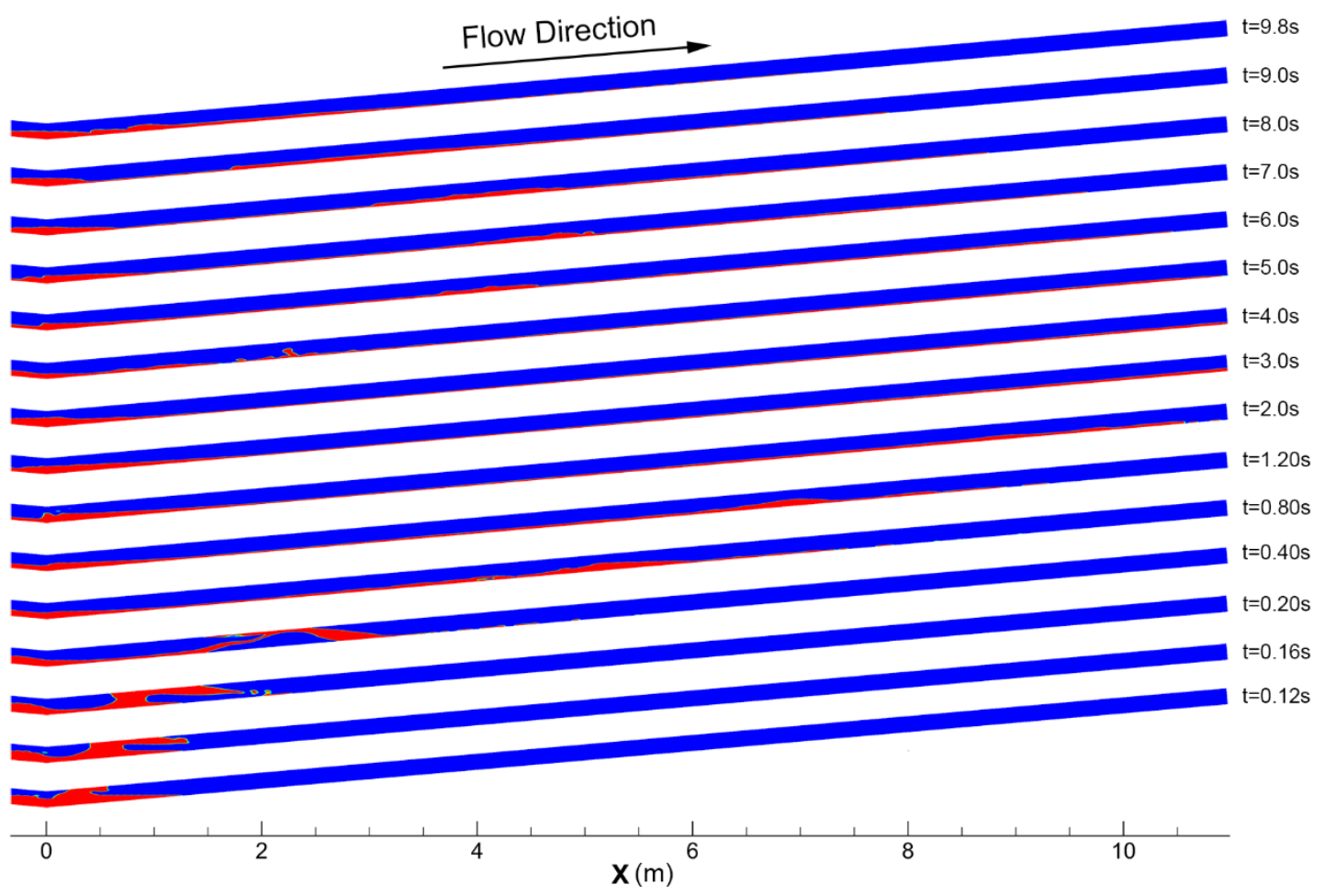

Fig. 5 Gas and liquid phase distribution along the uphill pipe

Fig. 6 shows the flow rate of the liquid phase at four cross-sections of the uphill pipe $(x=1000 \mathrm{~mm}, 3000 \mathrm{~mm}, 6000 \mathrm{~mm}, 7000 \mathrm{~mm})$ under the superficial gas velocity of $U_{G}=5.5 \mathrm{~m} / \mathrm{s}$. The flow rate presented the periodic alternation between the positive and negative in Fig. 6 (a) - (d). The positive flow rate means that the liquid motioned along the uphill section, while the negative flow rate represents the liquid refluxed. In Fig. 6 (c), the flow rate is equal to $0 \mathrm{~kg} / \mathrm{s}$ in this cross-section $(x=6000 \mathrm{~mm})$ at $t=11$ $\mathrm{s}-17 \mathrm{~s}$, and then a small amount of the liquid flowed through this cross-section of the uphill pipe. It illustrates that the liquid discontinuously flowes through this pipe crosssection. We can see from the Fig. 7 (d) that there was almost no liquid going through this pipe cross-section $(x=7000 \mathrm{~mm})$ after $t=10 \mathrm{~s}$. We, therefore, can conclude that the periodic reflux occurres between the elbow and the pipe cross-sections less than $x$ $=6000 \mathrm{~mm}$. 

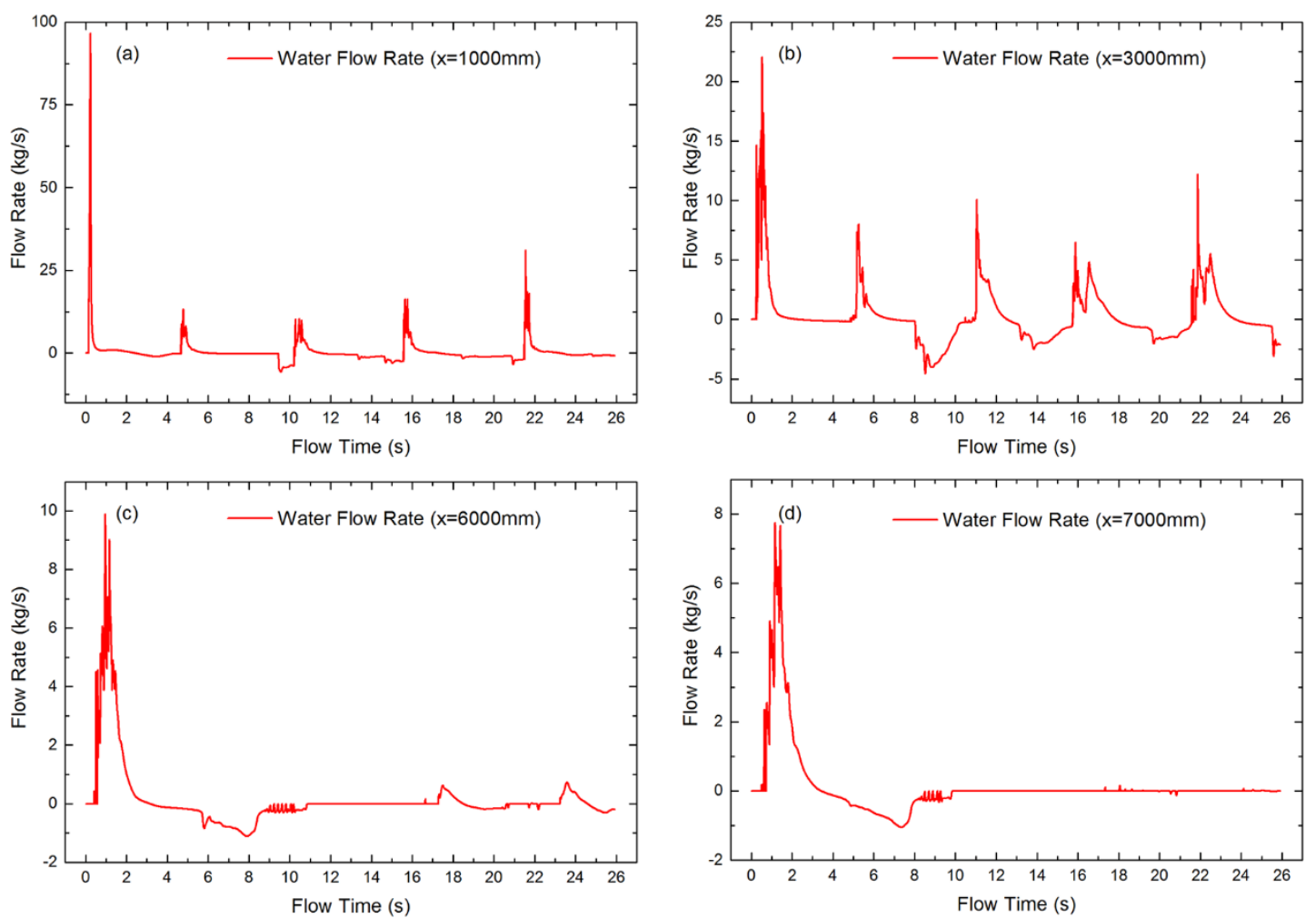

Fig. 6 Liquid flow rate in different cross-sections of the uphill pipe

Fig. 7 shows the liquid holdup in different cross-sections of the uphill pipe under the superficial gas velocity of $U_{G}=5.5 \mathrm{~m} / \mathrm{s}$. The fluctuation of the liquid holdup is shown in Fig. 7 (a) - (d). The liquid holdup showed the maximum peak of 1.0 in Fig. 7 (a). In other words, the liquids filled the whole cross-section of the uphill pipe at this point. As shown in Fig. 7 (b), the minimum peak of the liquid holdup was around 0.17 and the highest one was close to 0.40. In Fig. 7 (c) - (d), the maximum liquid holdup could reach 0.14 and the others were below 0.05 . The average thickness of the liquid layer tended to become thinner from the uphill cross-section of $x=1000 \mathrm{~mm}$ to $x=$ $7000 \mathrm{~mm}$. The shearing force of the gaseous phase on the liquid was gradually weakened, and the liquids no longer flowed out the pipe exit. 

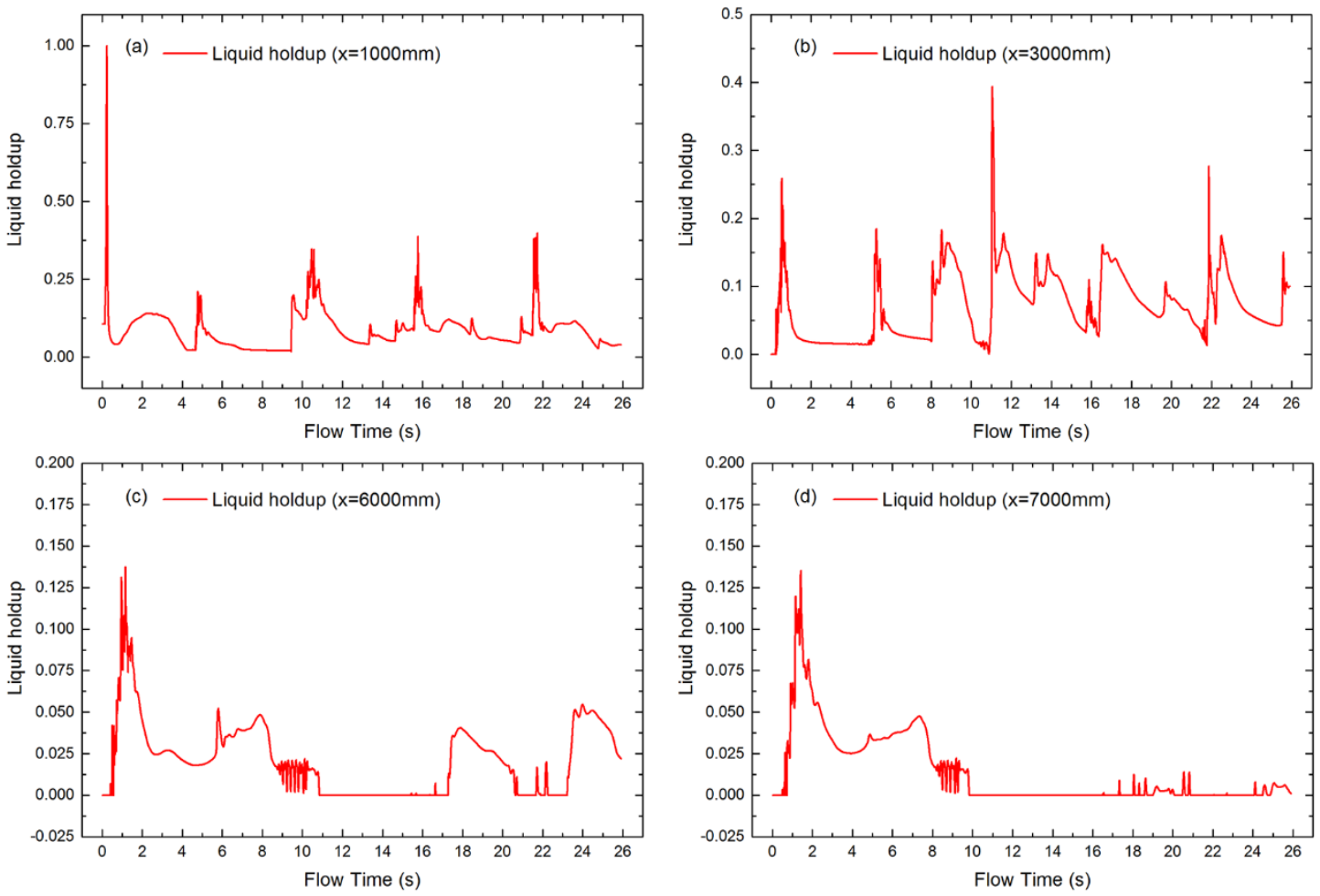

Fig. 7 Liquid holdup in different cross-section of the uphill pipe

The volume of the liquid was monitored in the numerical simulation and the results were presented in Fig. 8. The similar trends were obtained under three different inlet gas velocities. It can be seen that some liquids flowed out the pipe exit and the volume of liquid rapidly decreased in about 2 seconds. Later, the volume of the liquid was no longer changed. The volume percentages of the outflow liquid are approximately $20.16 \%, 28.4 \%, 31.58 \%$ under the superficial gas velocity of $U_{G}=5.5 \mathrm{~m} / \mathrm{s}, 6.5 \mathrm{~m} / \mathrm{s}, 7.5$ $\mathrm{m} / \mathrm{s}$, respectively.

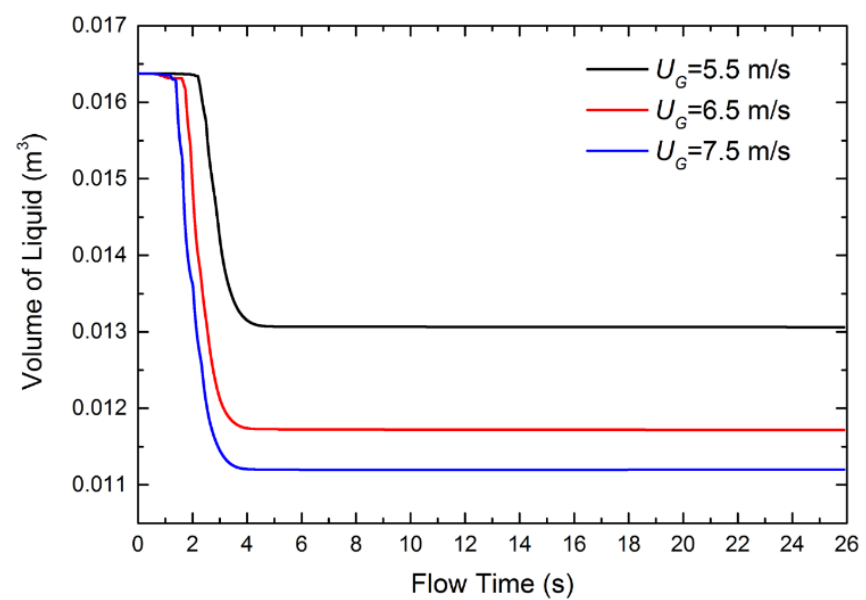


Fig. 8 Volume of the liquids in the terrain-inclined pipe

\section{Conclusions}

The VOF method and the RNG $k-\varepsilon$ turbulence model were used to simulate the gas-liquid two-phase flows within the terrain-inclined pipelines with deposited liquids. The flow area decreased because of the liquids gathered at the bottom of the pipe. It caused the increase of the gas velocity and the decrease of the static pressure, which generated the suction force above the gas-liquid interface. A wave crest formed and touched the top of the pipe under the action of the suction force around the elbow. The liquid blocked the cross-section of the pipe and correspondingly resulted in a large pressure drop. A certain amount of liquids can flow out the pipe exit carried by the gaseous phase. The volume percentages of the outflow liquids were $20.16 \%, 28.4 \%$, $31.58 \%$ under the superficial gas velocity of $5.5 \mathrm{~m} / \mathrm{s}, 6.5 \mathrm{~m} / \mathrm{s}, 7.5 \mathrm{~m} / \mathrm{s}$, respectively. The liquid periodically flowed and returned along the uphill section in the pipe when the liquid was no longer flowing out the pipe exit.

\section{Acknowledgements}

This work was supported by the National Natural Science Foundation of China (51606015), the Natural Science Foundation of Jiangsu Province, China (BK20150270), and the General Program of Natural Science Research Project of Jiangsu Province Universities and Colleges (15KJB440001). The research leading to these results has received funding from the People Programme (Marie Curie Actions) of the European Union's Seventh Framework Programme (FP7/2007-2013) under REA grant agreement no. 609405 (COFUNDPostdocDTU). 


\section{References}

[1] Taitel Y, Simkhis M, Tevelev A, Barnea D. Transient gas liquid flow in hilly terrain pipelines. International Journal of Multiphase Flow. 2016;86:21-7.

[2] Wen C, Li J, Wang S, Yang Y. Experimental study on stray current corrosion of coated pipeline steel. Journal of Natural Gas Science and Engineering. 2015;27:155561.

[3] Yang Y, Li Z, Wen C. Effects of alternating current on X70 steel morphology and electrochemical behavior. Acta Metall Sin. 2013;49:43-50.

[4] Taitel Y, Shoham O, Brill J. Transient two-phase flow in low velocity hilly terrain pipelines. International Journal of Multiphase Flow. 1990;16:69-77.

[5] Grolman E, Fortuin JM. Gas-liquid flow in slightly inclined pipes. Chemical Engineering Science. 1997;52:4461-71.

[6] Salhi Y, Si-Ahmed E-K, Legrand J, Degrez G. Stability analysis of inclined stratified two-phase gas-liquid flow. Nuclear Engineering and Design. 2010;240:1083-96.

[7] Goldstein A, Ullmann A, Brauner N. Characteristics of stratified laminar flows in inclined pipes. International Journal of Multiphase Flow. 2015;75:267-87.

[8] Gawas K, Karami H, Pereyra E, Al-Sarkhi A, Sarica C. Wave characteristics in gas-oil two phase flow and large pipe diameter. International Journal of Multiphase Flow. 2014;63:93-104.

[9] Al-Safran EM. Probabilistic modeling of slug frequency in gas/liquid pipe flow using the Poisson probability theory. Journal of Petroleum Science and Engineering. 2016;138:88-96. 
[10] Ferrari M, Bonzanini A, Poesio P. A 5 - equation, transient, hyperbolic, 1 dimensional model for slug capturing in pipes. International Journal for Numerical Methods in Fluids. 2017;85:327-62.

[11] Barnea D, Shoham O, Taitel Y, Dukler A. Flow pattern transition for gas-liquid flow in horizontal and inclined pipes. Comparison of experimental data with theory. International Journal of Multiphase Flow. 1980;6:217-25.

[12] Tzotzi C, Andritsos N. Interfacial shear stress in wavy stratified gas-liquid flow in horizontal pipes. International Journal of Multiphase Flow. 2013;54:43-54.

[13] Jia J, Babatunde A, Wang M. Void fraction measurement of gas-liquid twophase flow from differential pressure. Flow Measurement and Instrumentation. 2015;41:75-80.

[14] Arunkumar S, Adhavan J, Venkatesan M, Das S, Balakrishnan A.

Characterization of gas-liquid two phase flows using dielectric Sensors. Flow Measurement and Instrumentation. 2015;45:274-9.

[15] Abdulkadir M, Hernandez-Perez V, Lowndes I, Azzopardi B, Sam-Mbomah E. Experimental study of the hydrodynamic behaviour of slug flow in a horizontal pipe. Chemical Engineering Science. 2016;156:147-61.

[16] Dinaryanto O, Prayitno YAK, Majid AI, Hudaya AZ, Nusirwan YA, Widyaparaga A. Experimental investigation on the initiation and flow development of gas-liquid slug two-phase flow in a horizontal pipe. Experimental Thermal and Fluid Science. 2017;81:93-108.

[17] Bouyahiaoui H, Azzi A, Zeghloul A, Hasan A, Berrouk AS. Experimental investigation of a vertically downward two-phase air-water slug flow. Journal of Petroleum Science and Engineering. 2018;162:12-21. 
[18] Mouza A, Paras S, Karabelas A. CFD code application to wavy stratified gasliquid flow. Chemical Engineering Research and Design. 2001;79:561-8.

[19] Loilier P. Numerical simulation of two-phase gas-liquid flows in inclined and vertical pipelines: Cranfield University; 2006.

[20] Ekambara K, Sanders R, Nandakumar K, Masliyah J. CFD simulation of bubbly two-phase flow in horizontal pipes. Chemical Engineering Journal. 2008;144:277-88.

[21] Vallée C, Höhne T, Prasser H-M, Sühnel T. Experimental investigation and CFD simulation of horizontal stratified two-phase flow phenomena. Nuclear Engineering and Design. 2008;238:637-46.

[22] Verdin P, Thompson C, Brown L. CFD modelling of stratified/atomization gasliquid flow in large diameter pipes. International Journal of Multiphase Flow. 2014;67:135-43.

[23] Santim C, Gaspari E, Paternost G. A transient analysis of gas-liquid slug flow inside a horizontal pipe using different models. Journal of Petroleum Science and Engineering. 2017;151:62-76.

[24] Wang L, Yang Y, Liu C, Li Y, Hu Q. Numerical investigation of dynamic response of a pipeline-riser system caused by severe slugging flow. International Journal of Pressure Vessels and Piping. 2018;159:15-27.

[25] Hirt CW, Nichols BD. Volume of fluid (VOF) method for the dynamics of free boundaries. Journal of Computational Physics. 1981;39:201-25.

[26] Wen C, Cao X, Yang Y, Feng Y. Prediction of mass flow rate in supersonic natural gas processing. Oil \& Gas Science and Technology-Revue d'IFP Energies nouvelles. 2015;70:1101-9. 
[27] Yang Y, Wen C. CFD modeling of particle behavior in supersonic flows with strong swirls for gas separation. Separation and Purification Technology. 2017; 174:22-8.

[28] Fluent A. User's Guide Release 16.1. Ansys Inc. 2015.

[29] Brackbill J, Kothe DB, Zemach C. A continuum method for modeling surface tension. Journal of Computational Physics. 1992;100:335-54.

[30] Yang Y, Walther JH, Yan Y, Wen C. CFD modeling of condensation process of water vapor in supersonic flows. Applied Thermal Engineering. 2017;115:1357-62.

[31] Yang Y, Li A, Wen C. Optimization of static vanes in a supersonic separator for gas purification. Fuel Processing Technology. 2017;156:265-70.

[32] Wen C, Li A, Walther JH, Yang Y. Effect of swirling device on flow behavior in a supersonic separator for natural gas dehydration. Separation and Purification Technology. 2016;168:68-73.

[33] Yakhot V, Orszag SA. Renormalization group analysis of turbulence. I. Basic theory. Journal of Scientific Computing. 1986;1:3-51.

[34] Yang Y, Li J, Wang S, Wen C. Understanding the formation process of the liquid slug in a hilly-terrain wet natural gas pipeline. Journal of Environmental Chemical Engineering. 2017;5:4220-8.

[35] Heywood N, Richardson J. Slug flow of air - water mixtures in a horizontal pipe: Determination of liquid holdup by $\gamma$-ray absorption. Chemical Engineering Science. 1979;34:17-30. 